\title{
Is it wine, alcohol in general, or the social context of alcohol drinking that confers health benefits?
}

\author{
This article was published in the following Dove Press journal: \\ International Journal of Wine Research \\ II February 2010 \\ Number of times this article has been viewed
}

\author{
Kaarin J Anstey \\ Nicolas Cherbuin \\ Centre for Mental Health Research, \\ Australian National University, \\ Canberra, ACT, Australia
}

Correspondence: Kaarin J Anstey Centre for Mental Health Research, Australian National University, Canberra, ACT 0200, Australia

Tel +61261258410

Fax +6I 261250733

Email kaarin.anstey@anu.edu.au
It is always good news when scientists identify popular lifestyle factors that enhance well being and healthy aging. The scientific findings relating to low levels of alcohol consumption have generally fallen into this category, with numerous research studies now demonstrating that light to moderate drinkers have reduced risk of a number of adverse health outcomes in observational studies. ${ }^{1}$ For example, longitudinal studies have found that compared to nondrinkers and very heavy drinkers, light to moderate drinkers have reduced risk of cardiovascular disease, ${ }^{2}$ stroke,${ }^{3}$ dementia, ${ }^{4}$ and most importantly, mortality. ${ }^{5}$ These findings need to be balanced by the risks associated with alcohol consumption. For example, in women the risk of breast cancer appears to increase proportionally but modestly $(10 \%)$ with the number of daily alcoholic drinks. ${ }^{6}$ The risk of other cancers, particularly lung, mouth, and throat cancers and liver disease, is also increased, ${ }^{7,8}$ and alcohol consumption is associated with increased risk of injury in both young and older adults. ${ }^{9,10}$

Putative mechanisms for the benefits of alcohol include general anti-inflammatory actions of ethanol, and the ability of antioxidants present in wine to reduce oxidative stress partly responsible for brain cell damage, specifically resveratrol and proanthocyanidins. ${ }^{11}$ Ethanol consumption appears to be associated with higher levels of high-density lipoprotein cholesterol, and inhibition of platelet aggregation. Phenolic compounds have similar benefits and also appear to reduce endothelial adhesion, suppress cancer cell growth, and promote nitric oxide production, ${ }^{12}$ which has been shown to decrease blood pressure. ${ }^{13}$ Ethanol is also known to have an anxiolytic action which may contribute to lowering some negative effects of stress, ${ }^{14}$ but may also be involved in alcohol abuse mechanisms.

Some clinical trials and experimental studies have shown support for the beneficial effects of wine when compared with other alcoholic beverages. For example, a study of very old Chinese adults showed that moderate consumption of red wine, but not gin, decreased erythrocyte superoxide dismutase activity which indicates a beneficial antioxidant effect of wine over gin. ${ }^{15}$ There is also good evidence showing that alcohol in moderation increases bone density but findings from a large study surveying more than 30,000 Danish individuals only found a protective effect of wine and spirits on the risk of hip fracture while beer drinkers were at increased risk. ${ }^{16}$ However there is other emerging laboratory evidence from animal studies that beer may lead to reduced risk of carcinogenesis and osteoporosis; and that beer provides plasma with significant protection from oxidative stress. ${ }^{17}$ Clearly, further research is required to 
elucidate the range of potential benefits of different alcoholic beverage types, and the optimal quantities and frequencies of exposure.

There has been support for the specific benefits of wine over other alcoholic beverages in the field of dementia research. A study by Truelson ${ }^{18}$ showed that while total alcohol intake had no significant effect on risk of dementia, consumption of wine, but not beer or spirits, was significantly associated with a lower risk of dementia. However other research, while showing alcohol consumption in moderation is associated with reduced risk of cognitive decline, has not found specific beneficial effects of wine. For example, a study of 12,480 adults aged 70 years and older showed that women who consumed about one standard drink of alcohol per day had less cognitive decline than those who did not drink alcohol, but this was not related to beverage type. ${ }^{19}$

The interpretation of the varying research findings in relation to the health benefits of wine and other alcoholic beverages is further complicated by the fact that alcohol consumption is a social behavior and hence researchers measure the combined effect of behavior and biology rather than the pure biological effects of the beverage consumed. Benefit on health outcomes may not necessarily be via biochemical properties of wine, beer or spirits, but may be due to genetic differences that predispose to alcohol consumption or abstinence and which are associated with differing health outcomes, or to the social environment in which alcohol drinking takes place, or the social conditions of alcohol drinkers.

Two Danish studies have compared wine and beer drinkers and found that they differ in important sociodemographic and lifestyle characteristics. The first examined intelligence, personality, educational level and psychiatric symptoms and found that wine drinkers had better function in these psychosocial and sociodemographic domains. ${ }^{20}$ A second Danish study of supermarket purchases showed that those who bought wine, also bought healthy food items in general including olives, fruit, vegetables, low fat cheese and meat. ${ }^{21}$ In contrast, those who purchased beer were more likely to also purchase chips, sausages, preprepared meals, soft drinks, cold cuts, and sugar. These authors show that wine drinkers might differ from beer drinkers in terms of overall diet and socioeconomic status, and suggest that some of the benefits associated with drinking wine, may be due to these contextual variables, rather than the biochemical properties of wine itself. ${ }^{21}$ Alternative explanations are that different beverages are bought by individuals from varying age groups, different family members, or as part of different shopping trips (regular shopping for food, party supplies, etc.).

Emphasis on beverage type and the benefits of light to moderate drinking on average may distract from the problem of risky drinking behavior. Binge drinking any type of alcohol is detrimental to health, increasing the risk of injury using transport, operating machinery, while as a pedestrian, or through accidental falls. Alcohol dependence, regardless of beverage type, is associated with brain atrophy, and other serious medical conditions such as liver disease, increased risk of cancer. ${ }^{22}$

The intricacy of the interactions between the different factors discussed above should also not be underestimated. Research in this field is very preliminary and in future advice on alcohol consumption will likely be tailored based on numerous characteristics including age, gender, health status, genetic predisposition, diet, and many others.

Whilst public health policy has often focused on curbing alcohol consumption, the scientific evidence suggests that if the benefits of beverages such as wine could be harnessed and concentrated, then they may be developed as health enhancing nutriceuticals. The beneficial effects of such compounds have already been demonstrated in animals but while similar preparations are already available for human use their benefit has not yet been scientifically proven. ${ }^{23}$ From a public health perspective, developing accurate messages about alcohol and wine consumption is challenging because the health findings are complex. Nevertheless, it is important to communicate the benefits of light to moderate alcohol drinking and the antioxidant properties of specific beverages, in addition to providing recommendations about levels of safe and unsafe drinking.

\section{Disclosures}

Drs Anstey and Cherbuin are funded by NHMRC Fellowships \#366756 and 471501.

\section{References}

1. Goldberg DM, Soleas GJ, Levesque M. Moderate alcohol consumption: the gentle face of Janus. Clin Biochem. 1999;32:505-518.

2. Klatsky AL. Alcohol, cardiovascular diseases and diabetes mellitus. Pharmacol Res. 2007;55:237-247.

3. Mukamal KJ, Chung H, Jenny NS, et al. Alcohol use and risk of ischemic stroke among older adults: the cardiovascular health study. Stroke. 2005;36:1830-1834.

4. Anstey KJ, Mack HA, Cherbuin N. Alcohol consumption as a risk factor for dementia and cognitive decline: meta-analysis of prospective studies. Am J Geriatr Psychiatry. 2009;17:542-555.

5. Fuchs CS, Stampfer MJ, Colditz GA, et al. Alcohol consumption and mortality among women. N Engl J Med. 1995;332:1245-1250. 
6. Ellison RC, Zhang Y, McLennan CE, Rothman KJ. Exploring the relation of alcohol consumption to risk of breast cancer. Am J Epidemiol. 2001;154(8):740-747.

7. Pelucchi C, Gallus S, Garavello W, Bosetti C, La Vecchia C. Alcohol and tobacco use, and cancer risk for upper aerodigestive tract and liver. Eur J Cancer Prev. 2008;17(4):340-344.

8. Becker U, Deis A, Sorensen TI, et al. Prediction of risk of liver disease by alcohol intake, sex, and age: a prospective population study. Hepatology. 1996;23(5):1025-1029.

9. Hingson RW, Zha W, Weitzman ER. Magnitude of and trends in alcoholrelated mortality and morbidity among US college students ages 18-24, 1998-2005. J Stud Alcohol Drugs Suppl. 2009; (16):12-20.

10. Nordqvist C, Holmqvist M, Nilsen P, Bendtsen P, Lindqvist K. Usual drinking patterns and non-fatal injury among patients seeking emergency care. Public Health. 2006;120(11):1064-1073.

11. Sato M, Maulik N, Das DK. Cardioprotection with alcohol: role of both alcohol and polyphenolic antioxidants. Ann N Y Acad Sci. 2002;957:122-135.

12. de Lorimier AA. Alcohol, wine, and health. Am J Surg. 2000;180:357-361.

13. Kleinhenz DJ, Sutliff RL, Polikandriotis JA, et al. Chronic ethanol ingestion increases aortic endothelial nitric oxide synthase expression and nitric oxide production in the rat. Alcohol Clin Exp Res. 2008; 32(1):148-154.

14. Moberg CA, Curtin JJ. Alcohol selectively reduces anxiety but not fear: startle response during unpredictable versus predictable threat. J Abnorm Psychol. 2009;118(2):335-347.
15. Estruch R, Sacanella E, Mota F, et al. Moderate consumption of red wine, but not gin, decreases erythrocyte superoxide dismutase activity: A randomised cross-over trial. Nutr Metab Cardiovasc Dis. 2009; Oct 9. [Epub ahead of print].

16. Hoidrup S, Gronbaek M, Gottschau A, Lauritzen JB, Schroll M. Alcohol intake, beverage preference, and risk of hip fracture in men and women. Copenhagen Centre for Prospective Population Studies. Am J Epidemiol. 1999;149(11):993-1001.

17. Kondo K. Beer and health: preventive effects of beer components on lifestyle-related diseases. Biofactors. 2004;22:303-310.

18. Truelsen T, Thudium D, Gronbaek M. Amount and type of alcohol and risk of dementia: the Copenhagen City Heart Study. Neurology. 2002;59(9):1313-1319.

19. Stampfer MJ, Kang JH, Grodstein F. Alcohol and cognitive function in older women: reply. $N$ Engl J Med. 2005;352:1818-1819.

20. Mortensen EL, Jensen HH, Sanders SA, Reinisch JM. Better psychological functioning and higher social status may largely explain the apparent health benefits of wine: a study of wine and beer drinking in young Danish adults. Arch Intern Med. 2001;161:1844-1848.

21. Johansen D, Friis K, Skovenborg E, Gronbaek M. Food buying habits of people who buy wine or beer: cross sectional study. BMJ. 2006;332:519-522.

22. Cargiulo T. Understanding the health impact of alcohol dependence. Am J Health Syst Pharm. 2007;64:S5-S11.

23. Sadruddin S, Arora R. Resveratrol: biologic and therapeutic implications J Cardiometab Syndr. 2009;4(2):102-106.
International Journal of Wine Research

\section{Publish your work in this journal}

The International Journal of Wine Research is an international, peer-reviewed open-access, online journal focusing on all scientific aspects of wine, including: vine growing; wine elaboration; human interaction with wine; and health aspects of wine. The journal provides an open access platform for the reporting

\section{Dovepress}

of evidence based studies on these topics. The manuscript management system is completely online and includes a very quick and fair peer-review system, which is all easy to use. Visit http://www.dovepress.com/testimonials.php to read real quotes from some of our published authors.

Submit your manuscript here: http://www.dovepress.com/international-journal-of-wine-research-journalisease-journal 